\title{
EL ACCESO DE LA MUJER A LOS ESTUDIOS A TRAVÉS DE LAS ESCUELAS DE MAGISTERIO DE LA IGLESIA. EL CASO DE LA ESCUELA DE MAGISTERIO ESCUNI ENTRE 1970 Y 1983
}

\author{
Women's access to higher education through the Church's \\ teacher training colleges. The case of the Escuni Teacher \\ Training School between 1970 and 1983
}

\section{Félix Asenjo Gómez ${ }^{\alpha}$}

Fecha de recepción: 16/05/2020 • Fecha de aceptación: 29/03/2021

Resumen. La Iglesia en España ha desarrollado un papel destacado, en la labor de formación de maestros, especialmente a partir de la Ley de Educación Primaria de 1945, que le permitió la apertura y organización de escuelas de magisterio propias. El análisis de los datos estadísticos durante la década de los setenta de una de estas escuelas, el actual Centro Universitario de Magisterio Escuni, en Madrid, nos muestra las características de este tipo de centros, de su alumnado y de la presencia fundamental de mujeres, en lo que supuso su incorporación cada vez mayor a la sociedad, algo que también sucedió a partir de las Escuelas estatales, con las que se comparará. Vemos que estos estudios han constituido un acceso fundamental al mundo de la cultura y de la formación para las mujeres, y lo vemos reflejado no solo en las escuelas públicas sino también en las de la Iglesia.

Palabras clave: Mujeres; Educación de la mujer; Formación del magisterio; Escuelas de magisterio de la Iglesia; Escuni.

Abstract. The Church has played a prominent role in the field of teacher training in Spain, especially since the 1945 Primary Education Act, which allowed the Church to open and organize its own teacher training colleges. The analysis of the statistical data during the decade of the seventies of one of these schools, the current Centro de Estudios de Magisterio Escuni, in Madrid, shows us the characteristics of this type of school, of its student body and of

\footnotetext{
a Centro Universitario de Magisterio Escuni. Adscrito a la Universidad Complutense de Madrid. Avda. Nuestra Señora de Fátima, 102, 28047 Madrid, España. fasenjo4@alumno.uned.es
} 
the fundamental presence of women in them. This meant the increasing incorporation of women into society, something that also happened with their entry into the state public training schools, with which the private schools of the Church are compared. We observe that these studies have provided a fundamental access to the world of culture and higher education for women, an aspect that we see reflected not only in state schools but also in those of the Church.

Keywords: Women; Women's education; Teacher training; Teacher training schools of the Church; Escuni.

\section{INTRODUCCIÓN}

La actual tendencia en la investigación de historia de la educación demanda, entre otros, estudios sobre épocas más recientes y sobre aspectos hasta ahora marginados o poco transitados. Los estudios de género en España han sido tardíos y se han ido produciendo a partir de los años ochenta, ${ }^{1}$ gracias a la consolidación de la democracia en nuestro país y a la puesta en marcha de políticas igualitarias, aunque ya el foco de atención sobre el papel de las mujeres se había encendido anteriormente, a raíz del movimiento feminista de los años sesenta. ${ }^{2}$ Lejos de los análisis globales sobre cuestiones de género el objetivo de este trabajo es poder comprobar y analizar la afiliación femenina a la formación de magisterio en una escuela de maestros de la Iglesia en los años setenta, que sigue una tendencia que podemos rastrear desde los inicios del siglo XX y que ha representado siempre una vía principal de incorporación de la mujer a la sociedad.

Antes debemos aclarar que entendemos el «género» como una construcción cultural, como una categoría de análisis, ${ }^{3}$ pero no se pretende aquí indagar en su problemática, pasada o actual, sino tan solo aportar

\footnotetext{
1 Teresa Rabazas Romero y Sara Ramos Zamora, «La construcción del género en el franquismo y los discursos educativos de la Sección Femenina», Encounters on education=Encuentros sobre educación=Recontres sur l'éducation, 7 (2006): 44.

2 Pilar Ballarín Domingo, «La educación contemporánea de las mujeres», en Historia de la educación en la España contemporánea, diez años de investigación, eds. Jean Louis Guereña, Julio Ruiz Berrio y Alejandro Tiana Ferrer (Madrid: Ministerio de Educación, Cultura y Deporte, Centro de Investigación y Documentación Educativa, 1984), 174.

${ }^{3}$ Miryam Carreño, "Chicas en la postguerra, un análisis sobre el aprendizaje de género», Historia de la Educación: Revista Interuniversitaria 22-23 (2003-2004): 79-104.
} 
datos que sirvan de ejemplo en la representación de la mujer en la sociedad en un momento concreto, y en su lucha por crecer y aportar a la comunidad desde una posición más igualitaria, contribuyendo a hacer más visible el papel de las mujeres en la historia.

El objetivo de este artículo es comprender el presente del magisterio y de la presencia femenina en él preguntando al pasado cercano, casi inmediato. Se analiza el caso concreto de una escuela de magisterio de la Iglesia, intentando entender la situación de la formación de los maestros y especialmente de las mujeres, en un periodo crítico del siglo XX en España. Se utiliza la metodología de investigación histórico-educativa alternando el uso de fuentes secundarias y primarias, la revisión de artículos sobre temática de género y de formación de maestros, la consulta de la legislación pertinente, la comparación de datos estadísticos aportados por el Ministerio de Educación, junto al análisis de la información procedente de los archivos del Centro Universitario de Magisterio Escuni $^{4}$ y de la Escuela de Magisterio de La Almudena, que conforman el Archivo Histórico de Escuni (AHE).

El tema de la formación de maestros tiene una amplia tradición historiográfica, pero el caso de las escuelas de magisterio de la Iglesia no ha sido muy explorado por la investigación. Existe una tesis doctoral realizada sobre las escuelas de Madrid, leída en 1982, y otra posterior de 2003 sobre la escuela Don Bosco, así como algunos estudios particulares de escuelas concretas. ${ }^{5}$ Sin embargo, a pesar de que estas escuelas solo acogieron el 10\% del alumnado, creemos que su estudio puede aportarnos datos interesantes para completar el conocimiento del periodo histórico en el que se desarrollan.

\footnotetext{
${ }^{4}$ En el archivo de Escuni se encuentran, además de documentos del propio centro, otros informes generales procedentes del archivo del Secretariado de Escuelas de la Iglesia, dependiente de la Comisión Episcopal de Enseñanza. En adelante se citará como Archivo Histórico de Escuni (AHE).

${ }^{5}$ Genoveva Toledo, «Las escuelas de magisterio de la Iglesia en Madrid y su aportación a la formación de maestros (1945-1970)» (Tesis doctoral, Universidad Complutense de Madrid, 1984); Josefa Zaballos Crespo, Origen y evolución histórica de la escuela universitaria "Don Bosco" (Madrid: Servicio de Publicaciones de la Universidad Complutense, 2005); Juan Holgado Barroso, José Márquez de la Plata y Manuel Martín Riego, De la Escuela de Magisterio de la Iglesia al CES Cardenal Spínola CEU (1957-2011): historia de una institución (Sevilla: Fundación Universitaria San Pablo CEU, 2013); Joan Josep Matas Pastor, Las Hermanas de la Pureza de María en la formación de maestros y comunicadores. Historia del Centro de Enseñanza Superior Alberta Giménez (1974-2014) (Madrid: Universidad Pontificia Comillas, 2015).
} 
Para el marco cronológico tomamos dos hitos legislativos importantes en la configuración de nuestro sistema educativo. Por un lado, la Ley General de Educación de 1970, que marca un punto de inflexión y modernización en nuestra educación y fundamentalmente porque fue la que convierte las antiguas escuelas normales en escuelas universitarias de magisterio, un nivel educativo del que apenas habían disfrutado durante el periodo de la II República. Es también el momento en el que se fusionan las escuelas de la Iglesia y aparece la escuela de magisterio Escuni. Por el otro lado la Ley de Reforma Universitaria de 1983, al principio de la etapa socialista en un gobierno ya democrático, que renueva la universidad heredada del franquismo, le da autonomía y potencia las diplomaturas, entre las que se encuentra el magisterio. Supone un periodo no excesivamente amplio, aunque creemos que significativo. Las fechas que aparecen en las tablas y gráficos están dentro de este tramo cronológico, a pesar de que no siempre son coincidentes en los años de inicio y final pues proceden de fuentes documentales diversas que temporalmente no proporcionan datos para los mismos periodos exactos. A pesar de que la comparación total no es posible sí que son claras las tendencias que se muestran, que es lo que analizamos.

\section{SITUACIÓN DEL MAGISTERIO EN LA DÉCADA DE 1970. ALGUNOS DATOS ESTADÍSTICOS}

El progreso económico de la década de los sesenta y su repercusión en el cambio social en España se va a ver reflejado en la exigencia de una mejora educativa, que propiciará la aprobación de la Ley General de Educación de 1970. La nueva Educación General Básica, una etapa de educación obligatoria y gratuita desde los seis a los catorce años para todos, daba paso a un bachillerato unificado o a una formación profesional que no discriminaba por género. ${ }^{6}$ Quedaba atrás una época en la que había sido normal la separación tanto física como curricular entre niños y niñas. Los resultados del anuario estadístico de 1973 y 1976 registran la igualdad de matrícula de chicos y chicas en las etapas preescolar y obligatoria e incluso un número superior de matrícula femenina en el bachillerato, así como un aumento continuado de su presencia

\footnotetext{
${ }^{6}$ A pesar de la igualdad manifestada en la ley quedaba el resquicio de poder «matizar de acuerdo al sexo» los programas y orientaciones en la EGB y el Bachillerato, en los artículos 17.2 y 27.2 de la LGE.
} 
en la universidad. ${ }^{7}$ La progresión femenina en el acceso a los institutos de segunda enseñanza había ido en aumento cada año. ${ }^{8}$ Sin embargo, la igualdad en la tasa de escolarización, por ejemplo, en bachillerato, no se consiguió hasta el curso 1976-1977, y en la universidad hasta el curso 1987-1988. Aunque cada generación aspira a renovar y superar las situaciones vitales de sus predecesores, vemos ahora claramente que además «las hijas de familias españolas de 1960 tienen otra mentalidad, otro concepto de vida que sus madres y abuelas, y su campo de actividad se ha ampliado enormemente». ${ }^{9} \mathrm{El}$ aumento de mujeres en los estudios secundarios redundará en su mayor acceso al magisterio.

Si el acceso a la educación siempre estuvo restringido al ámbito masculino, secularmente y hasta bien entrado el siglo XIX, en el siglo XX se va a producir una progresiva feminización de los sistemas educativos, algo que por otra parte vemos que no solo afecta a España. ${ }^{10}$ De entre los diferentes estudios que se podían cursar en el siglo XIX la primera matrícula oficial que estuvo abierta a las mujeres fue la del magisterio. Su participación superaría a la del varón ya desde el primer cuarto del siglo XX y el proceso de feminización se intensificaría a lo largo de la segunda mitad del siglo, llegando en 1970 a suponer el 64,5\% del alumnado. ${ }^{11}$

La integración de las escuelas de magisterio en la universidad a partir de la ley de $1970,{ }^{12}$ supuso un cambio de denominación, pasando ahora a llamarse Escuelas Universitarias de Formación del Profesorado de Educación General Básica, también un cambio administrativo, por su dependencia de la universidad correspondiente, y por último un cambio

\footnotetext{
7 Pilar Ballarín Domingo, La educación de las mujeres en la España contemporánea (s. XIX-XX) (Madrid: Síntesis, 2001), 138.

8 Consuelo Flecha García, «Profesoras y alumnas en los institutos de segunda enseñanza (19101940)», Revista de Educación, no. extraordinario (2000): 269-294.

9 Rabazas y Ramos, «La construcción del género en el franquismo», 49.

10 Antonio Viñao Frago, Escuela para todos. Educación y modernidad en la España del siglo XX (Madrid: Marcial Pons, 2004), 246. Del tema de la feminización del magisterio también hablaron, entre otros, autores como Carlos Lerena Alesón, «El oficio de maestro. La posición y papel del profesorado de primera enseñanza», Sistema. Revista de Ciencias Sociales 50-51 (1982); y Félix Ortega Gutiérrez, «Un pasado sin gloria. La profesión de maestro», Revista de Educación 284 (1987).

11 Viñao, Escuela para todos, 251.

12 Según Disposición Transitoria 2. 3, de la Ley de 1970 BOE 6/08/1970. La transformación quedó regulada posteriormente por el Decreto 2293/1973 de 17 de agosto, BOE del 26 de septiembre de 1973.
} 
pedagógico, por la implementación de unos nuevos planes de estudios. El plan de estudios de 1971 fue conocido como «Plan experimental», y tardaría en refrendarse oficialmente seis años, con su publicación en el Boletín Oficial en 1977.13 Fue esta una época de numerosas inseguridades y dificultades para las nuevas escuelas de magisterio, tanto para las públicas como para las privadas. Y para la universidad en general, los años setenta fueron una etapa de movilizaciones y protestas, algo que venía propiciado por el momento histórico de cambio. Se mezclaban las reivindicaciones académicas con otras de tipo económico y político, y esto era así tanto para el alumnado como para el profesorado. Esta situación de inestabilidad se alargaría para las escuelas de magisterio hasta su conversión en facultades dentro de la universidad.

El número global de escuelas de magisterio pasó de 167 durante el curso 1966-1967 a 81 en 1975-1976, aunque hay que explicar que la reducción del número de escuelas no significó una reducción en el número de alumnos y alumnas, ya que de hecho aumentaron. La reducción de escuelas se produjo fundamentalmente en el sector privado, entre las que pertenecían a entidades de Iglesia. De los 110 centros no estatales existentes en 1966 se pasa a 25 en 1975, mientras que la cifra de los estatales se mantiene prácticamente igual. ${ }^{14}$ Un buen número de las escuelas de magisterio de la Iglesia funcionaban adheridas en instalaciones y servicios a colegios religiosos femeninos de enseñanza primaria y secundaria, de donde recibían su alumnado. Esto les permitía su mantenimiento económico, pues apenas llegaban al centenar de alumnas de media, número muy pequeño para su funcionamiento independiente. ${ }^{15} \mathrm{Y}$ cuando se exigió el bachiller superior para los estudios de magisterio se quedaron sin alumnado suficiente y tuvieron que optar por cerrar o fusionarse con otras escuelas.

Por otro lado, las cifras de mayor afluencia de alumnos y alumnas hacia los estudios de magisterio coincidirán con la implantación de las pruebas de acceso a la universidad, ${ }^{16}$ como veremos a continuación. Dentro de ese

\footnotetext{
13 Orden 13/06/1977, BOE del 25 de junio de 1977.

14 Joaquín Tena Artigas, Luis Cordero Pascual y José Luis Díaz Jares, La educación en España, análisis de unos datos (Madrid: Ministerio de Educación y Ciencia, 1978), 123.

15 Genoveva Toledo, «Las escuelas de magisterio de la Iglesia en Madrid», 251.

16 El examen de selectividad para el acceso a los estudios superiores fue una medida promovida en 1974 por el Ministerio de Educación y Ciencia, dirigido entonces por el ministro Cruz Martínez
} 
alumnado el grupo femenino seguirá siendo mayoría. Si en el curso 19661967 las mujeres representaban el 60\% de la matrícula total, para el curso 1975-1976 suponen más del 64\%, aumento producido a pesar de haber mejorado las condiciones económicas y sociales del colectivo de maestros, que parecía ser uno de los motivos por los que los varones acudían a él en menor medida que las féminas. ${ }^{17}$ En lo que respecta al tipo de centro, durante el curso 1975-1976 el 91\% de los alumnos acuden a centros estatales, con una ratio de 25 alumnos por profesor, cifra que sin embargo desciende hasta diez alumnos por profesor en las escuelas no estatales. ${ }^{18}$

\section{EVOLUCIÓN DEL ALUMNADO SEGÚN SEXO Y TIPO DE CENTRO}

El aumento del alumnado que accedía a los estudios de magisterio en España podemos verlo reflejado en la tabla I.

Tabla I. Evolución del total del alumnado de magisterio entre 1972-1982

\begin{tabular}{|c|c|c|}
\hline Año & Total alumnos & Variación \% \\
\hline $1972-1973$ & 45.531 & $-2,13$ \\
\hline $1973-1974$ & 44.560 & 32,54 \\
\hline $1974-1975$ & 59.058 & 19,43 \\
\hline $1975-1976$ & 70.534 & 19,36 \\
\hline $1976-1977$ & 84.186 & 15,25 \\
\hline $1977-1978$ & 97.028 & $-3,30$ \\
\hline $1978-1979$ & 93.830 & $-2,67$ \\
\hline $1979-1980$ & 91.328 & $-5,23$ \\
\hline $1980-1981$ & 86.551 & $-1,92$ \\
\hline $1981-1982$ & 84.886 & \\
\hline
\end{tabular}

Fuente: Fernando Muñoz Vitoria, El sistema de acceso a la universidad en España (1940-1990) (Madrid: Ministerio de Educación y Ciencia, CIDE, 1993), 284.

Esteruelas. Ley 30/1974 de 24 de julio sobre pruebas de aptitud para acceso a las Facultades, Escuelas Técnicas Superiores, Colegios Universitarios y Escuelas Universitarias. BOE del 26 de julio de 1974.

17 Tena, Cordero y Díaz, La educación en España, análisis de unos datos, 101.

18 Tena, Cordero y Díaz, La educación en España, análisis de unos datos, 123. 
Observamos que la afluencia de alumnos, chicos y chicas, a las nuevas Escuelas de Formación del Profesorado de EGB sufre un brusco ascenso entre los años 1974 y 1978, siendo especialmente importante el del curso $1974-1975$, donde experimenta una subida del $32,54 \%$ con respecto al año anterior, tendencia que, aunque no tan acusada, se mantiene en los tres siguientes cursos. Es el momento de entrada en vigor de la prueba de selectividad en la universidad española, examen que sin embargo no va a aplicarse inicialmente a los ahora estudios universitarios de magisterio. El alumnado que huye de esta prueba selectiva o que no consigue suficiente nota para los estudios deseados tiene una opción abierta en las escuelas de formación de maestros. En esta coyuntura, en la que la integración de la carrera de magisterio en la universidad es muy reciente y aún no está plenamente consolidada, cursar estos estudios ofrece un camino rápido para la obtención de un título superior, aunque sea con el nivel de diplomatura según el diseño universitario del momento, que da acceso directo al mundo laboral. Se configura, por tanto, como una vía muy útil y adecuada, especialmente para las aspiraciones de unas alumnas que contaban con pocas opciones de estudios tan socialmente aceptados. A partir del curso 1977-1978 la afluencia de alumnos, tanto hombres como mujeres, se estabiliza, tendiendo ligeramente a la baja, aunque consiguiendo doblar prácticamente en una década su número. Los datos de esta tabla trasladados a una gráfica nos muestran la rápida evolución ascendente y la posterior estabilización (gráfico I).

Gráfico I. Evolución alumnado de magisterio entre 1973-1982

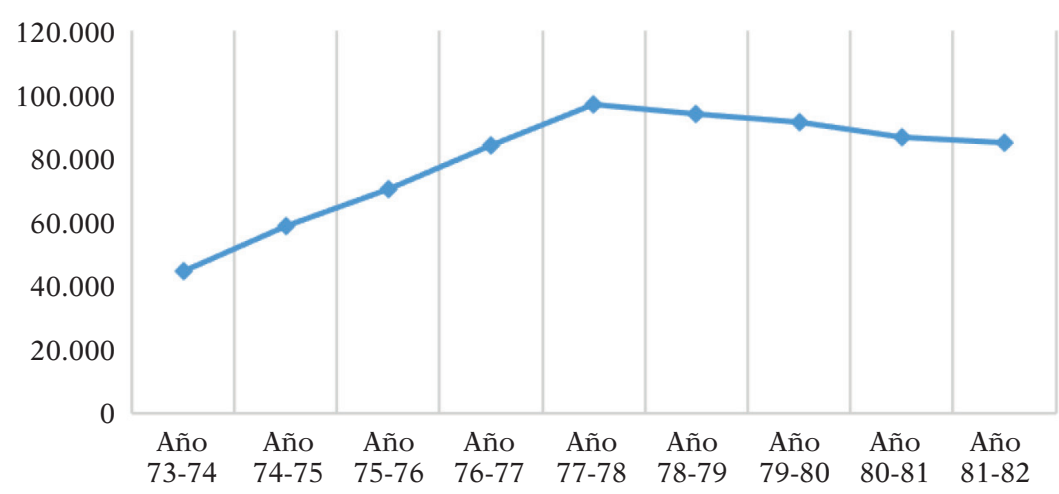

Datos muy interesantes se encuentran en el estudio sociológico sobre el magisterio realizado por Varela y Ortega para el Ministerio de 
Educación en 1984,19 y que se reproducen en la Tabla II y en el gráfico II. En el periodo estudiado de ocho años, entre 1973 y 1981, vemos que siempre es mayor la proporción femenina que la masculina, e incluso la población masculina desciende siete puntos en el cómputo global para el periodo estudiado. Y ese desequilibrio a favor de las mujeres es aún mayor en las escuelas privadas, con una diferencia frente a las públicas de unos seis puntos en el conjunto del periodo. Apreciamos un curioso pico en el curso 1974-1975 en las escuelas no estatales, donde se produce un aumento entre el grupo femenino a la par que un descenso similar en el sector masculino. Quizá la incertidumbre o el temor ante una prueba novedosa como la selectividad, que se implantaba ese año, hizo más mella entre el alumnado femenino que elegía los centros privados, y eso llevó a una afluencia mayor. Y una vez vista la experiencia de ese curso la tendencia se corrigió hacia la igualdad, según muestran los datos del resto de la década. En cualquier caso, constatamos que magisterio, tanto en centros públicos como en privados, sigue siendo una opción de estudios seguida mayoritariamente por el sector femenino de la población estudiantil.

Tabla II. Evolución del alumnado de magisterio por sexo y tipo de centro 1973-1981

\begin{tabular}{|l|c|c|c|c|c|c|}
\hline \multicolumn{1}{|c|}{ Curso } & \multicolumn{2}{|c|}{} & \multicolumn{2}{c|}{ Estatal } & \multicolumn{2}{c|}{ No estatal } \\
\hline $1973-1974$ & $\begin{array}{c}\text { Varones } \\
\%\end{array}$ & $\begin{array}{c}\text { Mujeres } \\
\%\end{array}$ & $\begin{array}{c}\text { Varones } \\
\%\end{array}$ & $\begin{array}{c}\text { Mujeres } \\
\%\end{array}$ & $\begin{array}{c}\text { Varones } \\
\%\end{array}$ & $\begin{array}{c}\text { Mujeres } \\
\%\end{array}$ \\
\hline $1974-1975$ & 37,17 & 62,87 & 37,56 & 62,44 & 31,70 & 68,30 \\
\hline $1975-1976$ & 36,24 & 63,76 & 36,22 & 63,78 & 21,42 & 78,58 \\
\hline $1976-1977$ & 35,42 & 64,58 & 35,39 & 64,61 & 35,90 & 64,10 \\
\hline $1977-1978$ & 32,91 & 67,09 & 32,93 & 67,07 & 32,84 & 67,16 \\
\hline $1978-1979$ & 33,39 & 66,61 & 33,45 & 66,55 & 32,88 & 67,12 \\
\hline $1979-1980$ & 34,26 & 65,74 & 34,66 & 65,34 & 31,57 & 68,43 \\
\hline $1980-1981$ & 33,37 & 66,63 & 33,95 & 66,05 & 29,55 & 70,45 \\
\hline
\end{tabular}

Fuente: Varela y Ortega, El aprendiz de maestro, 162.

\footnotetext{
19 Julia Varela y Félix Ortega, El aprendiz de maestro (Madrid, Ministerio de Educación y Ciencia, CIDE, 1984), 162.
} 


\section{Gráfico II. Evolución del alumnado de magisterio según el tipo de centro y sexo, 1973-1981}

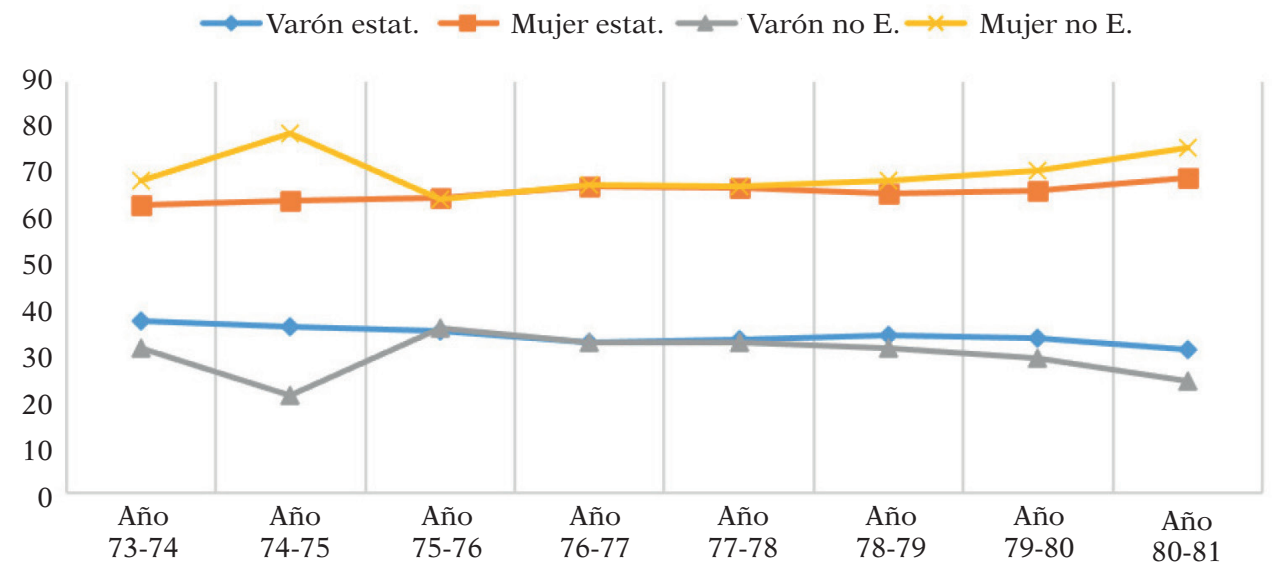

En la comparación entre escuelas estatales y privadas nos damos cuenta de que la evolución del alumnado corre de forma pareja, sin apenas variación, a lo largo del periodo analizado, entre los cursos de 1973 y 1981. Y lo mismo ocurre en la proporción entre hombres y mujeres que se deciden por estos estudios, siendo siempre superior la proporción femenina. Cada una de las modalidades sigue atrayendo a un tipo de población de manera muy fija, pero el conjunto de alumnos que se deciden por estos estudios, en cualquiera de las opciones, se mantiene constante tanto en número como en afiliación por género. Apreciamos también que las líneas tienden a ser más divergentes al final del periodo, de manera que la ya mayoritaria elección de estos estudios por parte de las mujeres se sigue acentuando, mientras que tiende a la baja la de los hombres. Y también vemos que esta tendencia es común tanto en las escuelas públicas como privadas. Confirmamos que magisterio, en la década de los setenta, sigue siendo una carrera fundamentalmente femenina.

\section{EL ALUMNADO DE LAS ESCUELAS DE MAGISTERIO DE LA IGLESIA}

Los alumnos y fundamentalmente alumnas de las escuelas de la Iglesia tuvieron en un principio un destino claro en los propios colegios religiosos, como maestros y maestras para esos centros. En esa función formadora de sus propios docentes, antes del cambio provocado 
por la reforma de los planes de estudio en 1967, existieron escuelas de la Iglesia "de todos los calibres», ${ }^{20}$ algunas muy humildes y otras con muy buen nivel y perfecta organización. Pero las que subsistieron tras la reforma de la ley «lo hicieron tan decorosamente que sus alumnos compitieron con las Normales oficiales en plan de igualdad y con resultados parecidos en las prueba de madurez». ${ }^{21}$ En esta segunda etapa de existencia no le van a faltar, por tanto, estudiantes a estas escuelas.

Para poder seguir mostrando cómo evoluciona la población estudiantil que se decide por los estudios de magisterio vemos en la tabla III la afluencia de alumnos y alumnas a estas escuelas de la Iglesia, que recordemos, ya imparten el nuevo plan de estudios experimental. Observamos una progresión similar a la experimentada en las escuelas estatales, aunque con unos porcentajes de aumento que resultan espectaculares, especialmente en el curso 1974-1975, y en menor medida en los tres cursos posteriores. Si comparamos las gráficas I y III vemos la similitud en el ascenso de estudiantes en ambas opciones, pero terminando en una tendencia al alza en las escuelas de la Iglesia y a la baja en las públicas. En las escuelas de la Iglesia se parte de una población muy pequeña, pues de alguna manera están naciendo de nuevo. Acaban de ser renovadas y adaptadas a la nueva legislación. Por un lado, debemos tener en cuenta que apenas suponen el 10\% del alumnado total del magisterio español, pero por otro, los datos nos dicen que la oferta de estas escuelas tiende a consolidarse rápidamente, e incluso con apenas 23 centros en el año 1976 consiguen un número de alumnos superior al que tuvieron entre las 114 que existían en el curso 1967-1968, momento en que se renovó el plan de estudios. ${ }^{22}$

\footnotetext{
${ }^{20}$ Manuel de Guzmán, Vida y muerte de las escuelas normales (Barcelona: PPV, 1986) 206.

21 Guzmán, Vida y muerte de las escuelas normales, 209.

22 «I Reunión de Obispos, representantes de las entidades titulares y directivos de las Escuelas de la Iglesia del Profesorado de Educación General Básica», Madrid, 20 de octubre de 1976, p. 3, carpeta Informes y Memorias, caja 4, AHE.
} 
Tabla III. Evolución de alumnado de magisterio en las escuelas de la Iglesia

\begin{tabular}{|l|c|c|}
\hline \multicolumn{1}{|c|}{ Curso } & Número alumnos & Variación \% \\
\hline $1973-1974$ & 1395 & 138,8 \\
\hline $1974-1975$ & 3332 & 56,4 \\
\hline $1975-1976$ & 5213 & 29,7 \\
\hline $1976-1977$ & 6760 & 21,8 \\
\hline $1977-1978$ & 8234 & $-1,4$ \\
\hline $1978-1979$ & 8118 & 6,6 \\
\hline $1979-1980$ & 8651 & 2,2 \\
\hline $1980-1981$ & 8841 & 11,9 \\
\hline $1981-1982$ & 9891 & 0,5 \\
\hline $1982-1983$ & 9942 & \\
\hline
\end{tabular}

Fuente: AHE. Elaboración propia. ${ }^{23}$

Gráfica III. Alumnado de las escuelas de magisterio de la Iglesia 1973-1983

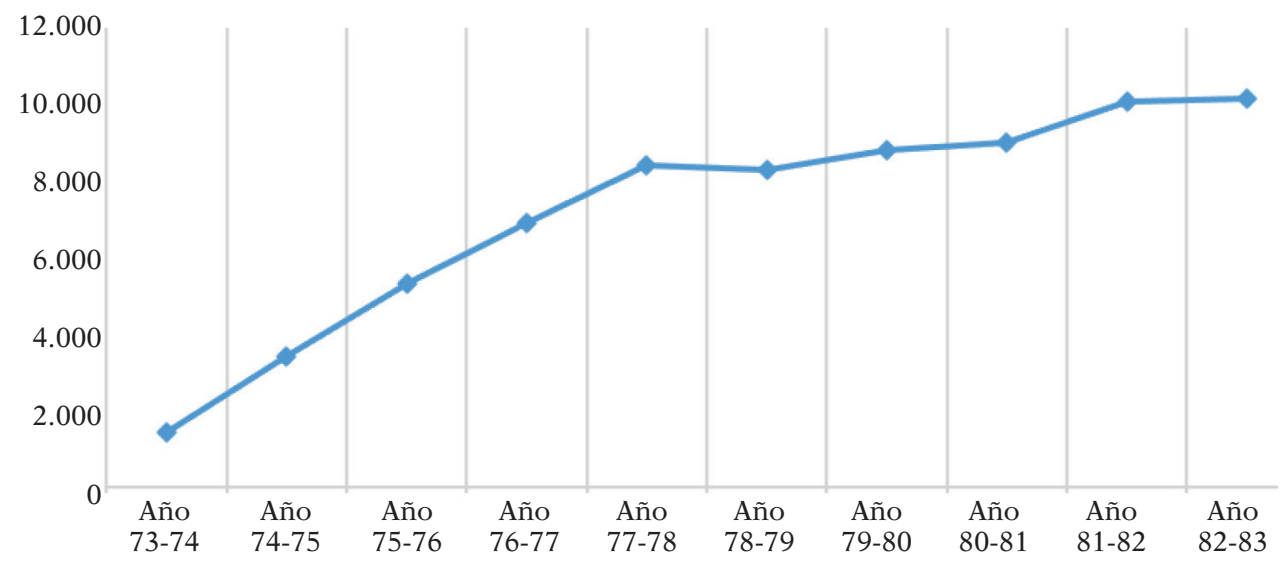

23 «IV Asamblea de Escuelas Universitarias de Magisterio de la Iglesia», 25 de marzo de 1983, p. 13, carpeta Asambleas, caja 4, AHE. Los datos aportados en esta estadística solo recogen los alumnos que inician los nuevos planes educativos a partir de 1973 y no incluyen los alumnos presentes en las Escuelas de la Iglesia que pertenecían al plan de 1967. Este plan irá progresivamente extinguiéndose a partir de 1971. 
Teniendo siempre presente la distancia en el número de alumnos entre los dos tipos de escuelas, públicas y privadas, en la siguiente gráfica IV se observa el espectacular aumento de alumnado que en el curso 1974-1975 acude a las escuelas privadas, justamente en el año en el que se implantó la selectividad. Vemos también que esta tendencia al alza fue corrigiéndose poco a poco en los cursos posteriores hasta llegar a una evolución paralela a la pública a partir de 1979. Con una década de recorrido desde que se iniciara la implantación de la Ley General de Educación de 1970 y se reorganizaran las escuelas de magisterio incorporadas a la universidad, encontramos que en el curso 1981-1982 son casi diez mil los alumnos y alumnas repartidos en 23 escuelas de la Iglesia, con una media de 450 por escuela, y con una ligera proyección de aumento. Podemos entender que ofrecían una propuesta de trabajo que era aceptada por los aspirantes a maestro y adecuada a la nueva legislación que se había planteado. Su reconversión desde las antiguas escuelas que la Iglesia empezara a fundar a raíz de la ley de 1945 estaba teniendo éxito.

\section{Gráfica IV. Comparación de alumnos en escuelas estatales y no estatales}

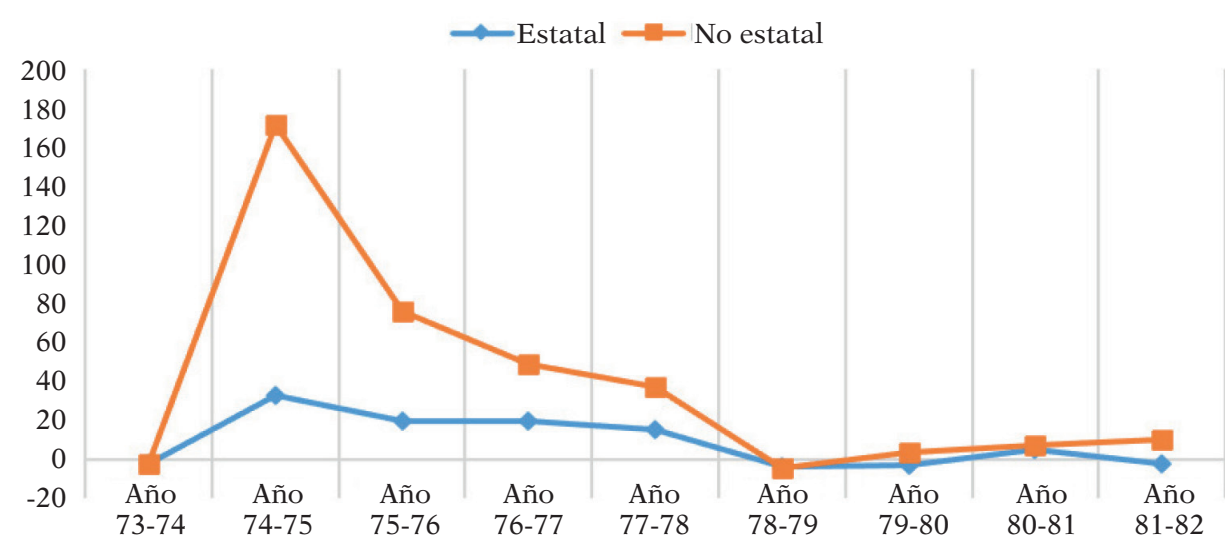

Fuente: Véase nota. ${ }^{24}$

En la tabla IV aportamos ahora un dato más para el análisis del alumnado de las escuelas de la Iglesia: los alumnos religiosos, tanto hombres como mujeres, que en muchas de las escuelas originales habían sido

\footnotetext{
${ }^{24}$ Fuentes utilizadas: los datos de la tabla II, de Julia Varela y Félix Ortega, para las escuelas estatales y los de la tabla III del AHE para las escuelas no estatales. Elaboración propia.
} 
numerosos, no llegan al 2,5\% en el curso 1982-1983. Apenas hay diferencia entre hombres y mujeres religiosos, un $0,94 \%$ frente a un $1,5 \%$. Representan pues una minoría en el conjunto total. Se constata que cada vez es menor el número de vocaciones religiosas y esto también se refleja en la pequeña proporción que ocupan entre los alumnos de las escuelas de magisterio de la Iglesia.

Tabla IV. Alumnado religioso-seglar. Escuelas de la Iglesia. Curso 1982-1983

\begin{tabular}{|l|c|c|}
\hline Religiosos (hombres y mujeres) & 245 & $2,48 \%$ \\
\hline Seglares (hombres y mujeres) & 9.667 & $97,52 \%$ \\
\hline Total & 9.912 & $100 \%$ \\
\hline
\end{tabular}

\begin{tabular}{|c|c|c|c|c|c|}
\hline \multicolumn{3}{|c|}{ Hombres } & \multicolumn{3}{c|}{ Mujeres } \\
\hline Religiosos & Seglares & Total & Religiosas & Seglares & Total \\
\hline $0,94 \%$ & $19,51 \%$ & $20,46 \%$ & $1,5 \%$ & $78,01 \%$ & $79,53 \%$ \\
\hline
\end{tabular}

Fuente: Véase nota. ${ }^{25}$

Por lo que respecta al profesorado, igual tendencia a la baja se observa entre el colectivo religioso. Tan solo un dato, en el curso 19821983 el 37\% del profesorado de las escuelas de magisterio de la iglesia era religioso, frente a un 63\% seglar. ${ }^{26}$ En cuanto al sexo, el 47,2\% eran mujeres y el 52,7\% eran hombres, porcentaje prácticamente igual al de las escuelas públicas. ${ }^{27}$ Por estos años en los centros educativos de los diferentes niveles que la Iglesia tiene aumentará muy significativamente el profesorado no religioso.

Tan clara como la tendencia hacia un alumnado seglar vemos en esta misma tabla IV la característica femenina de quienes eligen estos estudios en las escuelas de la Iglesia. En estos centros, supone casi el 80\% del total, frente a un $68,8 \%$ que se daba en las escuelas públicas, como

\footnotetext{
${ }^{25}$ Fuente: «IV Asamblea de Escuelas Universitarias de Magisterio de la Iglesia», 25 de marzo de 1983, pp. 7 y 16, carpeta Asambleas, caja 4 AHE. Elaboración propia.

26 «Síntesis del acta de la Asamblea de directores y directores adjuntos», Madrid, 17 de noviembre de 1984, p. 7, carpeta Datos Estadísticos, caja 6, AHE.

27 Varela y Ortega, El aprendiz de maestro, 167.
} 
hemos visto antes (tabla II). Seguimos comprobando la afinidad de las mujeres por los estudios de magisterio, o al menos la poca afluencia por parte de los hombres, en la línea que ya apuntábamos de feminización de la profesión. Este dato es fruto probablemente de la continuación de esa ideología dominante que atribuye a las mujeres especiales cualidades para la labor educativa, a la vez que ve su tarea como la continuación de la realizada en el hogar. Y la característica femenina se ve aún más acentuada en las escuelas de magisterio de la Iglesia. La explicación puede estar en que la mayoría de ellas surgieron a partir de colegios religiosos femeninos y se produce una continuidad en este sentido, la sociedad las sigue viendo como instituciones educativas para mujeres.

Otro de los aspectos interesantes de estudio es la clase social que alimenta el alumnado de magisterio. ${ }^{28}$ Observando los datos de la tabla V vemos que el grupo ampliamente mayoritario de población que acude a las escuelas estatales de magisterio es de clase media baja, un 66\% en las escuelas estatales y un 41,6\% en las de la Iglesia.

Tabla V. Procedencia social según la profesión de los padres. Comparación escuelas de magisterio estatales y Escuelas de la Iglesia. Curso 1982-1983

\begin{tabular}{|l|c|c|}
\hline \multicolumn{1}{|c|}{ Clase social } & Magisterio estatal & Escuelas de la Iglesia \\
\hline Alta & 7,80 & 12,23 \\
\hline Media alta & 4,00 & 27,77 \\
\hline Media baja & 66,01 & 41,63 \\
\hline Baja & 16,01 & 18,74 \\
\hline
\end{tabular}

Fuentes: Varela y Ortega, El aprendiz de maestro, 166 y 207; y elaboración propia a partir de «IV Asamblea de Escuelas Universitarias de Magisterio de la Iglesia», del 25 de marzo de 1983, pp. 11,12, caja 4, carpeta Asambleas, AHE.

\footnotetext{
28 Para analizar las clases sociales, en el caso del magisterio estatal, nos valemos de los datos aportados por el Instituto Nacional de Estadística, INE, Estadística universitaria en España, curso 197980, que aparecen en el estudio de Julia Varela y Félix Ortega, El aprendiz de maestro, 166 y 207. En cuanto a los datos de las Escuelas de la Iglesia utilizamos el documento del AHE: caja 4, carpeta Asambleas, "IV Asamblea de Escuelas Universitarias de Magisterio de la Iglesia», del 25 de marzo de 1983, pp. 11,12. En este documento aparece una estadística realizada por el Secretariado de Escuelas de la Iglesia tomando como base probable los barómetros del Centro de Investigaciones Sociológicas, CIS y los datos del INE de principios de la década de los ochenta para agrupar las diferentes profesiones en clases sociales, de manera coincidente con las clasificaciones del Ministerio.
} 
Constatamos que los de magisterio han sido tradicionalmente unos estudios ligados a las clases subalternas, media baja y baja, que ven en ellos una salida laboral que mejora su estatus, a la vez que cierta facilidad para su realización, según la imagen que de estos estudios se ha tenido tradicionalmente. Es una profesión elegida por alumnos cuyos padres proceden de los estratos bajos de las clases medias, correspondiente a profesiones modestas, como pueden ser funcionarios y asalariados pero con cierta estabilidad laboral y una pequeña capacidad de ahorro, destacando entre ellos los de procedencia rural (pequeño propietario agrícola, trabajador autónomo, ganadero), padres que pueden ver en el magisterio una manera de que sus hijos, y especialmente sus hijas, puedan subir un peldaño en la escala social. ${ }^{29}$ Pero ya sabemos que esta no es una característica única del magisterio en España, sino algo que ocurre en el conjunto de países europeos. ${ }^{30}$ Para el caso de las mujeres el acceso al magisterio ha supuesto siempre una posibilidad de independencia y elevación social, mucho mayor que en el caso masculino. Ello explica que el contingente femenino sea superior, característica que a la vez repercutirá en la feminización de la profesión. ${ }^{31}$ Las no muy numerosas opciones de estudio para las mujeres tan socialmente aceptadas como el magisterio contribuyen a llenar las escuelas normales. La alternativa de dependencia familiar o de reducción al papel de ama de casa hacen deseables unos estudios que procuran opciones laborables suficientemente interesantes para ellas.

La comparación de la extracción social entre las escuelas estatales y de la Iglesia presenta tendencias similares en cuanto a su distribución por grupos, pero hay interesantes diferencias en las proporciones. Vemos unos mayores datos registrados por las escuelas de la Iglesia entre los grupos de clase media alta y alta, por ejemplo, un $4 \%$ para la estatal frente a un $27 \%$ para las de la Iglesia en el tramo de la media alta. Y entre la clase media alta y alta suman casi tanto como el porcentaje de la media baja. Esta diferencia con las escuelas públicas podría representar

\footnotetext{
${ }^{29}$ Félix Ortega y Agustín Velasco, La profesión de maestro (Madrid: Ministerio de Educación y Ciencia, CIDE, 1984), 39.

${ }^{30}$ Gilbert de Landsheere, La formación de los enseñantes del mañana (Madrid: Narcea, 2. ${ }^{\text {a edición, }}$ 1978), 178-180. Aporta datos de diferentes países europeos en los que coincide el estrato social medio y bajo para la procedencia de los aspirantes al magisterio.
}

${ }^{31}$ Landsheere, La formación de los enseñantes del mañana, 182. 
la preferencia tradicional de estos grupos sociales por la enseñanza privada, que la verían como un privilegio, ya que pueden pagar una cuota adicional. Aunque curiosamente también son superiores los datos de asistencia a esta enseñanza privada de la clase más baja, un 18,74\% frente a un $16 \%$, lo que podría explicarse por la posibilidad que ofrecen estas escuelas de tener alumnos becados internamente. Sus responsables son conscientes de que sus alumnos tienen que pagar un coste mayor, unas cuotas mensuales que, a pesar de todo, siempre se procuraron bajas. ${ }^{32}$

Como ejemplo de la procedencia social del alumnado, en lo que se refiere a la escuela de magisterio de la Iglesia Escuni, vemos cómo en sus archivos se afirma que «solo un porcentaje inferior al 10\% pertenecen a familias cuyos padres tienen una profesión liberal; la gran mayoría son pues hijos de obreros, agricultores, pequeños industriales, administrativos o funcionarios». ${ }^{33} \mathrm{Y}$ en un documento posterior se dice que no se deben subir las cuotas de los alumnos porque «dos tercios de la escuela pertenecen a familias que están en la mitad inferior de la escala social». ${ }^{34}$ Se es consciente, por tanto, del tipo de alumnos que se tienen y de su origen y posibilidades.

Aunque podríamos preguntarnos si las escuelas de la Iglesia representan una alternativa real a la escuela pública o tan solo atienden a aquellos sectores que esta no recoge (a pesar de todo, los números son claros a favor de la pública), lo cierto es que las escuelas de la Iglesia, de manera consciente, no pretenden crecer indefinidamente, aumentar en exceso el número de sus alumnos ni crear instalaciones y plantillas de profesores que después se conviertan en un problema. Hemos visto en la gráfica III que después de un rápido crecimiento inicial, a partir de 1978 la afluencia se estabiliza. Mantienen una matrícula cerrada y pretenden una enseñanza de calidad y una preparación que posibilite el acceso al

\footnotetext{
32 Las Escuelas de la Iglesia siempre fueron deficitarias, déficit que cubren las instituciones promotoras por entender su carácter social. En el año 1980 la cuota media aportada por los alumnos cubre el 71,98\% del gasto total de las escuelas. Además, el 9,94\% de alumnos pagan cuotas inferiores a la media o están totalmente becados. «III Asamblea de directores, jefes de estudio y presidentes de patronato de las Escuelas Universitarias de la Iglesia del Profesorado de EGB», 12 de diciembre de 1980, p. 23, carpeta Asambleas, caja 4, AHE.

33 «Informes sobre el actual momento de las Escuelas Universitarias de Magisterio de la Iglesia», 1979, p. 4, carpeta Informes y memorias, caja 4, AHE.

34 «Informe de la visita realizada a la Escuela Universitaria de Magisterio de la Iglesia Escuni de Madrid», p. 2, carpeta Informes y memorias, caja 4, AHE.
} 
mundo laboral de sus egresados, lo que suponen redundará en una llegada de alumnado suficiente para mantenerse. Tratan principalmente de cumplir la misión fundacional con la que nacieron de formar maestros cristianos, ${ }^{35}$ los que las propias instituciones necesitaban, razón por la que siempre fueron apoyadas por la jerarquía religiosa.

\section{EL CASO DE LA ESCUELA DE MAGISTERIO DE LA IGLESIA ESCUNI}

Ya sabemos que las escuelas de magisterio de la Iglesia surgen a raíz de la Ley de Educación Primaria de 1945. Tendrán una etapa de amplio desarrollo que finalizará con otra ley, la de 1970, que aparece tras un periodo de profundos cambios económicos y sociales en España. Durante ese periodo en Madrid llegaron a fundarse hasta nueve escuelas. Las dos primeras, en 1948, fueron la femenina de Ntra. Sra. de la Almudena, regentada por la Institución Teresiana y la masculina de San Juan Bautista de la Salle, que dirigían los HH. De la Doctrina Cristiana en Griñón (Madrid). Después se fundaron siete escuelas más, todas ellas femeninas. La posterior escuela de magisterio Escuni será fruto de la fusión de varias de ellas. En concreto, la Escuela de San Vicente de Paúl regentada por las Hijas de la Caridad, la Escuela de La Inmaculada de las RR. MM. Escolapias, la Escuela de la Madre Ana Mogas, de las RR. Franciscanas de la Madre del Divino Pastor, y la Escuela del Sagrado Corazón de las RR. del Sagrado Corazón. En 1972 se unió también la ya citada Escuela de la Almudena, formando ESCUNI (Escuelas Unidas). Todas ellas son congregaciones o instituciones de Iglesia dedicadas fundamentalmente a la enseñanza que tuvieron su propia pequeña escuela de magisterio. En el proceso de unificación tuvo que ver el tamaño de cada escuela, pero fundamentalmente fue una decisión individual de cada congregación por continuar con la tarea del magisterio. Todas las existentes en ese momento fueron convocadas a una reunión para tratar el tema, que se celebró el 11 de mayo de 1970. La reunión estuvo presidida por el director del Secretariado de Escuelas de Magisterio de la Iglesia, el hermano Mencía, ${ }^{36}$ y en ella se vio que

\footnotetext{
35 «III Asamblea de directores, jefes de estudio y presidentes de patronato de las Escuelas Universitarias de la Iglesia del Profesorado de EGB», 12 de diciembre de 1980, pp. 16,18, carpeta Asambleas, caja 4, AHE.

36 Emiliano Mencía de la Fuente fue un religioso que perteneció a la congregación de los Hermanos de las Escuelas Cristianas-La Salle y fue director del Secretariado para las Escuelas de Magisterio de la Iglesia entre 1968 y 1988, dependiente de la Comisión Episcopal de Enseñanza.
} 
no era conveniente en ese momento una reducción tan drástica en una sola escuela, con la fusión de todas las escuelas existentes. Los representantes de las que no querían fusionarse se retiraron, pues tenían otros planes para sus centros, y continuó la reunión con aquellas que estaban dispuestas, las ya citadas anteriormente. ${ }^{37}$ Vemos que en la recién creada Escuni quedarán reunidas cinco de las nueve escuelas madrileñas que existieron, todas ellas femeninas. Otras dos habían desaparecido a raíz del cambio de planes de estudio en 1967. Y las dos restantes seguirán caminos independientes. Una, la de San Juan Bosco, dirigida por las Hijas de María Auxiliadora, se fusionará con la escuela masculina de San José que los salesianos tenían en Guadalajara, formando la escuela mixta de Don Bosco. ${ }^{38}$ Y por su parte la escuela de La Salle se trasladará en 1970 de Griñón a Aravaca (Madrid), convirtiéndose también en escuela mixta desde esa fecha. ${ }^{39}$ Vemos pues, que serán tres las entidades que a partir de 1970 continúen la labor de las escuelas de magisterio de la Iglesia en Madrid, las escuelas de La Salle, Don Bosco y Escuni.

Escuni se convirtió en la escuela que servía de base y modelo donde experimentar cambios e iniciar procesos que luego se trasladaban a otras escuelas de España. En ella confluían algunas características, como la de haber surgido de la unión de varias anteriores, estar ubicada en la capital, próxima al Ministerio de Educación donde se tramitaban todos los expedientes, y próxima también al Secretariado de Escuelas de la Iglesia, que dirigía los procesos de fusión y marcaba las líneas metodológicas. Pero, además, era escuela modelo "por el dinamismo con el que arrancó y su preocupación por la calidad» ${ }^{40}$ educativa que se propuso desde el inicio, lo que pronto redundará en el rápido crecimiento de su alumnado, como veremos después.

\footnotetext{
37 Genoveva Toledo, «Las escuelas de magisterio de la Iglesia en Madrid y su aportación a la formación de maestros (1945-1970)» (Tesis doctoral, Universidad Complutense de Madrid, 1984) 303.

38 Del origen y evolución de esta escuela se da cumplida noticia en la tesis doctoral de Zaballos Crespo, J. Origen y evolución histórica de la escuela universitaria «Don Bosco» (Madrid: Servicio de Publicaciones de la Universidad Complutense, 2005). Actualmente esta escuela está integrada en el Centro de Estudios Superiores Don Bosco

$39 \mathrm{Su}$ origen y desarrollo está recogido en el libro que celebra su 50 aniversario. Fortunato Alcalde, Cincuenta años de historia (1948-1998). Forjando educadores. Escuela Universitaria L Salle. (Madrid: Imprenta Villena, 2001). Actualmente esta escuela está integrada en el Centro Superior de Estudios Universitarios La Salle, en Aravaca (Madrid)

40 Emiliano Mencía, «Escuelas unidas-escuela universitaria». En Veinticinco años abriendo horizontes. Escuni 1970-1995, dir. Dolores María et al (Madrid, Imprenta Artegraf, S.A. 1995), 22-27.
} 
El desarrollo industrial de la década de los sesenta propiciará el auge de las ciudades y el crecimiento de una clase social media. La búsqueda de una mayor racionalidad en el uso de los recursos incluirá también la búsqueda de la eficacia del sistema educativo. ${ }^{41} \mathrm{Y}$ al igual que hay que formar mano de obra cualificada para la industria también es una necesidad mejorar la formación de los maestros y maestras. En 1967 se reforman las escuelas de magisterio, con la exigencia del bachillerato superior para su acceso y con un nuevo plan de estudios. A partir de ese momento, y sobre todo desde la nueva Ley de Educación de 1970, los estudios se convertirán en mixtos y todas las escuelas, tanto de la Iglesia como del Estado, empezarán a recibir alumnos y alumnas en las mismas aulas, cursando los mismos estudios, de manera que la posibilidad de obtener una diplomatura universitaria con acceso directo al mundo laboral también resultará atractiva para los chicos, lo que redundará en su progresiva incorporación. La ley de 1970 marca un antes y un después en la educación española y esto es especialmente cierto para las escuelas de magisterio. Parece que la transformación no fue fácil, ya fueran públicas o privadas. En el caso de estas últimas, para el curso 1972-1973 solo se autorizó a diez escuelas de la Iglesia a impartir, con carácter experimental, el Plan de Estudios de las Escuelas del Profesorado de EGB ${ }^{42}$ Dos años después, para el curso 1974-1975, ascendían a veintitrés las autorizadas a impartir el Plan Universitario.

La clave de la transformación en las escuelas de la Iglesia, aparte de la coyuntura política que influye en la realidad educativa, habría que buscarla en el trabajo sistemático que ya se venía haciendo a nivel del profesorado desde la segunda mitad de la década de los sesenta. Desde la jerarquía eclesiástica, a partir del curso 1968-1969, se había iniciado una política de fusiones dirigida a disminuir su número y a potenciar la calidad exigida en los nuevos planes oficiales. ${ }^{43}$ Algunas cerraron, pues atendían a un alumnado muy poco numeroso y sin perspectivas de crecimiento, otras decidieron que tendrían más posibilidades trabajando juntas y se unieron para adaptarse y sobrevivir (en algunas ciudades

\footnotetext{
41 Manuel de Puelles Benítez, «Oscilaciones de la política educativa en los últimos cincuenta años: reflexiones sobre la orientación política de la educación», Revista Española de Pedagogía 192 (1992): 316.

42 Orden del 21 de septiembre de 1972, BOE del 7 de noviembre de 1972.

43 «Las Escuelas de la Iglesia del Profesorado de EGB en el año académico 1971-72. Memoria», 15 de noviembre de 1972, p. 9, carpeta Informes y Memorias, caja 4, AHE.
} 
como Madrid, Barcelona o Valencia había hasta seis o siete instituciones de este tipo). Ya hemos visto que la escuela de magisterio Escuni es fruto de la fusión de varias de las existentes en la capital. El proceso de extinción de las distintas escuelas, en unos casos, y de fusión en otros, va a ser dirigido desde la Conferencia Episcopal, concretamente desde el Secretariado de Escuelas Universitarias de Magisterio de la Iglesia, a la sazón dirigido por el ya citado hermano de La Salle Emiliano Mencía. Recordemos que las distintas escuelas habían ido surgiendo a partir de 1945 y habían llegado a suponer hasta 118, repartidas por todo el territorio nacional, incluidos los dos archipiélagos. Cada escuela era independiente y tenía como superior jerárquico al obispo de la diócesis local. Escuni, para el curso 1972-1973 fue una de las primeras diez escuelas de toda España a las que el Ministerio de Educación autorizó a impartir el nuevo Plan de Estudios de las Escuelas del Profesorado de EGB ${ }^{44}$ Surge así en este contexto renovador y nace con un nuevo estilo de vida y de trabajo, intentando llevar a la práctica las novedosas teorías pedagógicas de los años setenta. Emiliano Mencía tendrá un papel clave en la organización y desarrollo de las escuelas de la Iglesia en este periodo. Diseñó y fomentó una renovación pedagógica basada en la educación personalizada, que en esos momentos estaba en boga, teniendo como fuente principal la experiencia del jesuita Pierre Faure en Francia. Lo hará en colaboración con el Movimiento Somosaguas, desarrollado por la Institución Teresiana. La «Experiencia Somosaguas» representa un singular intento de renovación educativa que pretendió trasladar la iniciativa de aprendizaje al propio alumno, haciéndole consciente de su individualidad a la vez que también altera la función del maestro, como facilitador de ese aprendizaje. ${ }^{45}$

\section{ANÁLISIS DEL ALUMNADO DE LA ESCUELA DE MAGISTERIO ESCUNI}

Hemos comprobado que el conjunto de la población que acude a las escuelas de magisterio aumenta a partir de la nueva ley de 1970 y que, en apenas cinco cursos, entre 1973 y 1978, duplica su población (tabla I). El

\footnotetext{
44 Orden de 21 de septiembre de 1972. BOE del 7 de noviembre de 1972.

45 Para entender el Movimiento Somosaguas puede consultarse: Pierre Faure, «Estudios generales. La enseñanza personalizada, orígenes y evolución». Revista de Educación, 247 (1976): 5-10; Irene Gutiérrez Ruiz, Experiencia Somosaguas. (Madrid: Iter Ediciones, 1971); Irene Gutiérrez Ruiz, El maestro de la Experiencia Somosaguas. Tendencias pedagógicas, 14, (2009), 181-189.
} 
aumento de alumnado en las escuelas de la Iglesia fue aún más espectacular. La progresiva implantación de los cursos del Plan experimental y la confianza en la validez oficial de los títulos dieron lugar a que el número de alumnos se duplicara en tres años, teniendo siempre en cuenta que estas escuelas partían de una población muy pequeña y que al final de la década de los setenta solo recogían al 10\% del total de alumnos de magisterio.

Los siguientes datos son interesantes: en el curso 1981-1982 se contaban 9.891 alumnos en el conjunto de escuelas de magisterio de la Iglesia. La media de alumnos entre todas las escuelas era de unos 450 . El número de profesores total era de 525, con una media de 24 profesores por escuela y con una ratio media de 17 alumnos por profesor. La ratio profesor/alumno en las escuelas públicas se situaba en 25 , en el curso 1980-1981.46 Por esas mismas fechas Escuni contaba con un total de 848 alumnos, con 39 profesores y una ratio de 22 alumnos por profesor, números como vemos superiores a la media del conjunto de escuelas de la Iglesia y que dan idea de su pujanza. ${ }^{47}$ Estos datos los vemos representados en la tabla VI y en el gráfico V. El problema en estos momentos en Escuni lo representaba el espacio, que había quedado muy escaso para el volumen de alumnado admitido.

La ubicación de los centros educativos y el propio diseño de la construcción escolar no son arbitrarios, siempre tienen un significado. ${ }^{48} \mathrm{En}$ el caso de las escuelas de magisterio de la Iglesia lo habitual fue que compartieran el espacio y los recursos de los colegios de segunda enseñanza que tenían las diferentes congregaciones religiosas. Esa misma característica va a continuar dándose en la ubicación de Escuni, que, si bien no puede decirse que fuera fruto del azar, sí tuvo que ir adaptándose a las necesidades de cada momento. Entre 1970 y 1980 Escuni va a tener tres sedes diferentes. Los dos primeros años se alojó provisionalmente en los locales de la escuela de San Vicente de Paúl, en la

\footnotetext{
46 Varela y Ortega, El aprendiz de maestro, 170.

47 «IV Asamblea de Escuelas Universitarias de Magisterio de la Iglesia», 25 de marzo de 1983, carpeta Asambleas, caja 4, AHE.

48 Agustín Escolano Benito, «La arquitectura como programa. Espacio-escuela y curriculum». Historia de la Educación vol. XII-XIII (1993-94): 97-120; Antonio Viñao Frago, «Del espacio escolar y la escuela como lugar. Propuestas y cuestiones», Historia de la Educación vol. XII-XIII (1993-94): 17-74
} 
calle García de Paredes, propiedad de las Hijas de la Caridad, una de las congregaciones fundadoras de Escuni. Eran los momentos en los que aún convivía el alumnado del plan de estudios de 1967 con el del nuevo de 1971. Ante el aumento de alumnos y alumnas, con gran ilusión y pretensión de permanencia, se trasladó en 1972 a unas dependencias del colegio del Cardenal Spínola, en la calle Dolores Povedano, un colegio que la congregación de las Esclavas del Divino Corazón había terminado de construir en 1960. Incluso esta congregación entró a formar parte del patronato de Escuni. Era un edificio nuevo, ubicado en el barrio de Chamartín de la Rosa, donde permaneció hasta 1977. En esta fecha unos nuevos planes urbanísticos afectaron al edificio y ante el aumento continuo de estudiantes tendrá que realizar un nuevo traslado. Para iniciar el curso siguiente la Diócesis de Madrid les cede parte del seminario menor, sito en la calle Jerte, donde a partir de entonces contó con el espacio necesario para el alumnado que acogía en esos momentos, pero que a la larga también acabaría siendo insuficiente. ${ }^{49}$

Tabla VI. Datos totales de alumnado en Escuni, curso 1974-1982

\begin{tabular}{|c|c|c|c|c|c|}
\hline Curso & Mujeres & $\%$ & Hombres & $\%$ & Total \\
\hline $1974-1975$ & 183 & 94,3 & 11 & 5,7 & 194 \\
\hline $1975-1976$ & 190 & 91,3 & 18 & 8,7 & 208 \\
\hline $1976-1977$ & 339 & 86,0 & 55 & 14,0 & 394 \\
\hline $1977-1978$ & 525 & 82,1 & 114 & 17,9 & 639 \\
\hline $1978-1979$ & 561 & 81,5 & 127 & 18,5 & 688 \\
\hline $1979-1980$ & 588 & 79,6 & 151 & 20,4 & 739 \\
\hline $1980-1981$ & - & & - & & 721 \\
\hline $1981-1982$ & - & & - & & 848 \\
\hline
\end{tabular}

Fuentes: Genoveva Toledo, «Las escuelas de magisterio de la Iglesia en Madrid», Apéndice II, 242 y elaboración propia a partir de AHE: caja 4, carpeta Asambleas.

\footnotetext{
${ }^{49}$ Escuni se trasladaría a su actual sede, en la avenida Nuestra Sra. De Fátima, n. ${ }^{\circ} 102$, en septiembre de 1998
} 


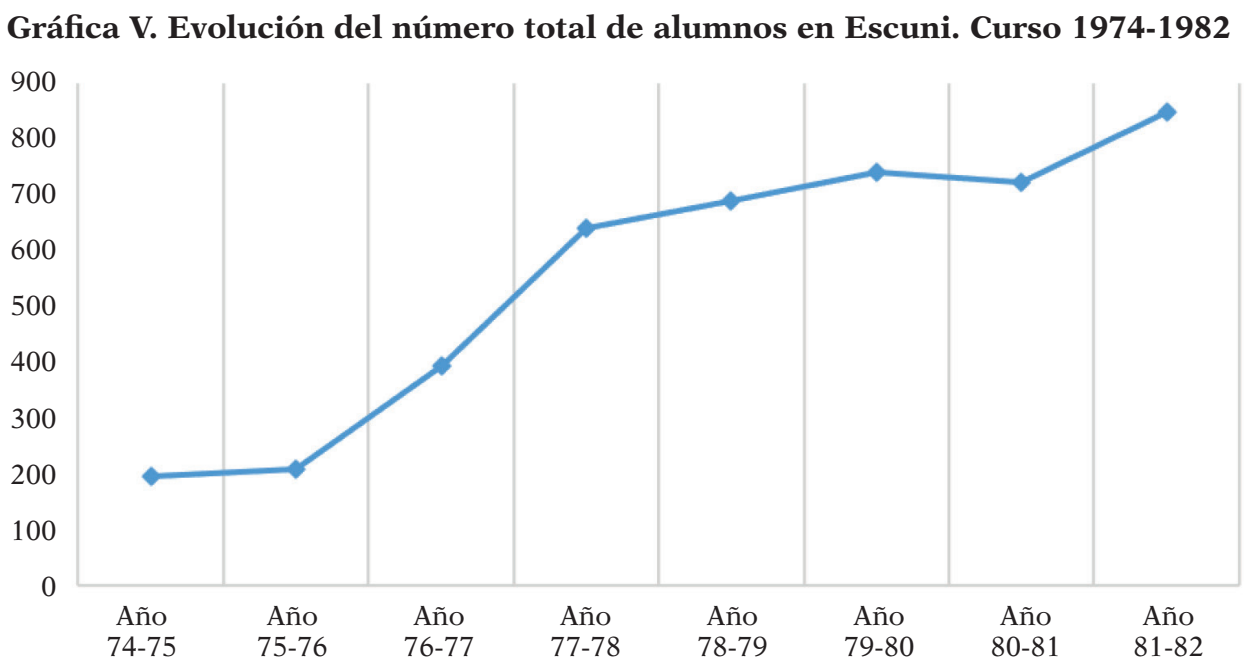

En cuanto a la distribución por sexo (tabla VII y gráficos VI y VII) vemos que Escuni parte de un alumnado prácticamente femenino -un 94\% en 1974- pues había surgido a partir de la fusión de varias escuelas de magisterio femeninas que tenían colegios únicamente de chicas, para llegar al curso 1979-1980 a unos porcentajes de 79,6\% frente a un $20,4 \%$ de chicos, más cercanos a los de la media de escuelas de la Iglesia, donde la proporción entre mujeres y hombres era de un $70,4 \%$ frente a un $29,6 \%$. En ese mismo curso en las escuelas estatales, como hemos visto en la tabla III, la proporción era del $66,3 \%$ frente a un 33,3\%. Lo interesante es observar, en la gráfica VI, que el gran salto de alumnado producido a partir del año 1977 corresponde a población femenina, que es la que aporta la mayor parte del aumento del volumen estudiantil, pues la población masculina, aunque avanza, lo hace de manera mucho más contenida. Seguimos comprobando la aceptación y preferencia femenina por estos estudios, especialmente en las escuelas de la Iglesia y entre ellas en Escuni. Probablemente los mayores porcentajes femeninos de Escuni puedan deberse a una cierta tradición o inercia en la percepción que se tiene de esta escuela, pues es la heredera de escuelas solamente femeninas. En otros casos es diferente, pues hay escuelas de magisterio de la Iglesia que son fruto de la unión de antiguas escuelas masculinas y femeninas, como es por ejemplo el caso de la escuela Don Bosco de Madrid, surgida de las ramas masculina y femenina de los salesianos. 
Tabla VII. Comparación del alumnado por sexo entre el total de escuelas de la Iglesia y Escuni

\begin{tabular}{|c|c|c|c|c|}
\hline & \multicolumn{2}{|c|}{$\begin{array}{c}\text { Total de Escuelas Magisterio de } \\
\text { la Iglesia }\end{array}$} & \multicolumn{2}{c|}{ Escuni } \\
\hline Curso & Mujeres \% & Hombres \% & Mujeres \% & Hombres \% \\
\hline $1974-1975$ & 78,6 & 21,4 & 94,3 & 5,7 \\
\hline $1975-1976$ & 64,1 & 35,9 & 91,3 & 8,7 \\
\hline $1976-1977$ & 67,2 & 32,8 & 86,0 & 14,0 \\
\hline $1977-1978$ & 67,1 & 32,9 & 82,1 & 17,9 \\
\hline $1978-1979$ & 68,4 & 31,6 & 81,5 & 18,5 \\
\hline $1979-1980$ & 70,4 & 29,6 & 79,6 & 20,4 \\
\hline
\end{tabular}

Fuente: Elaboración propia a partir de IV Asamblea de Escuelas Universitarias de Magisterio de la Iglesia», 25 de marzo de 1983, carpeta Asambleas, caja 4, AHE.

\section{Gráfica VI. Evolución de alumnos en Escuni por sexo. Curso 1974-1980}
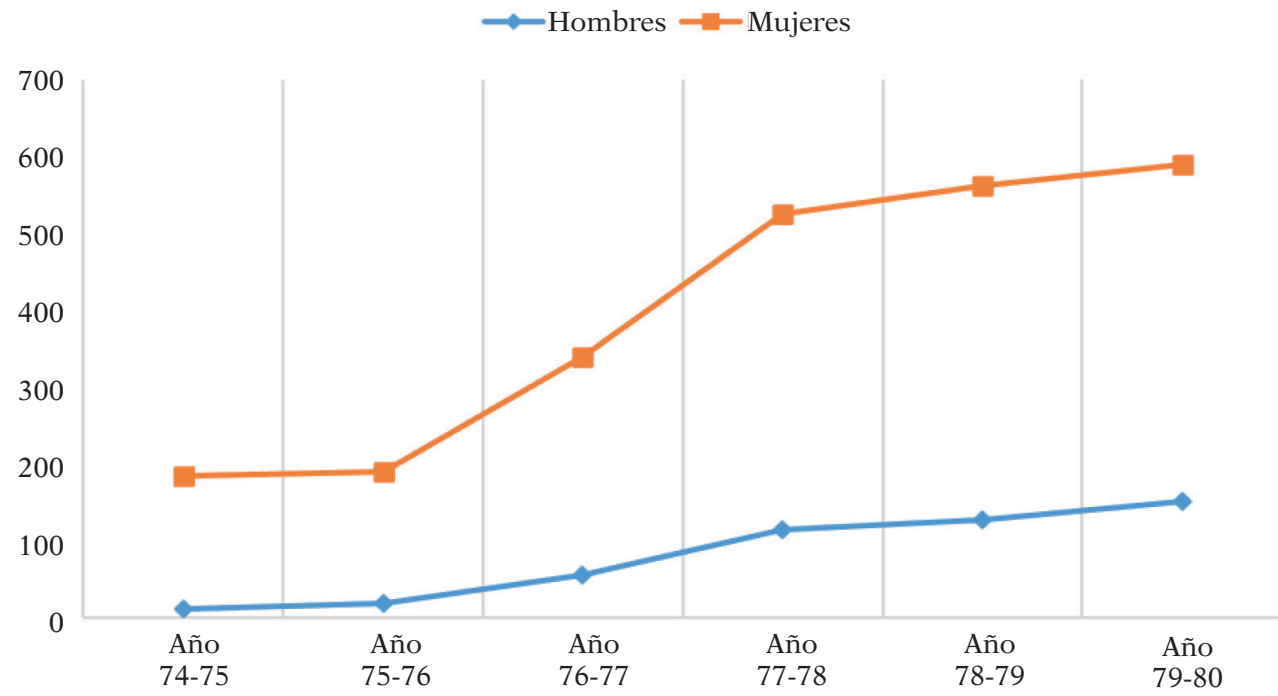


\section{Gráfica VII. Comparación del alumnado por sexo entre escuelas de la Iglesia y Escuni}

$\multimap$ Muj. EMI - -Var. EMI $\rightarrow-$ Muj. Escuni $\rightarrow$ Var. Escuni

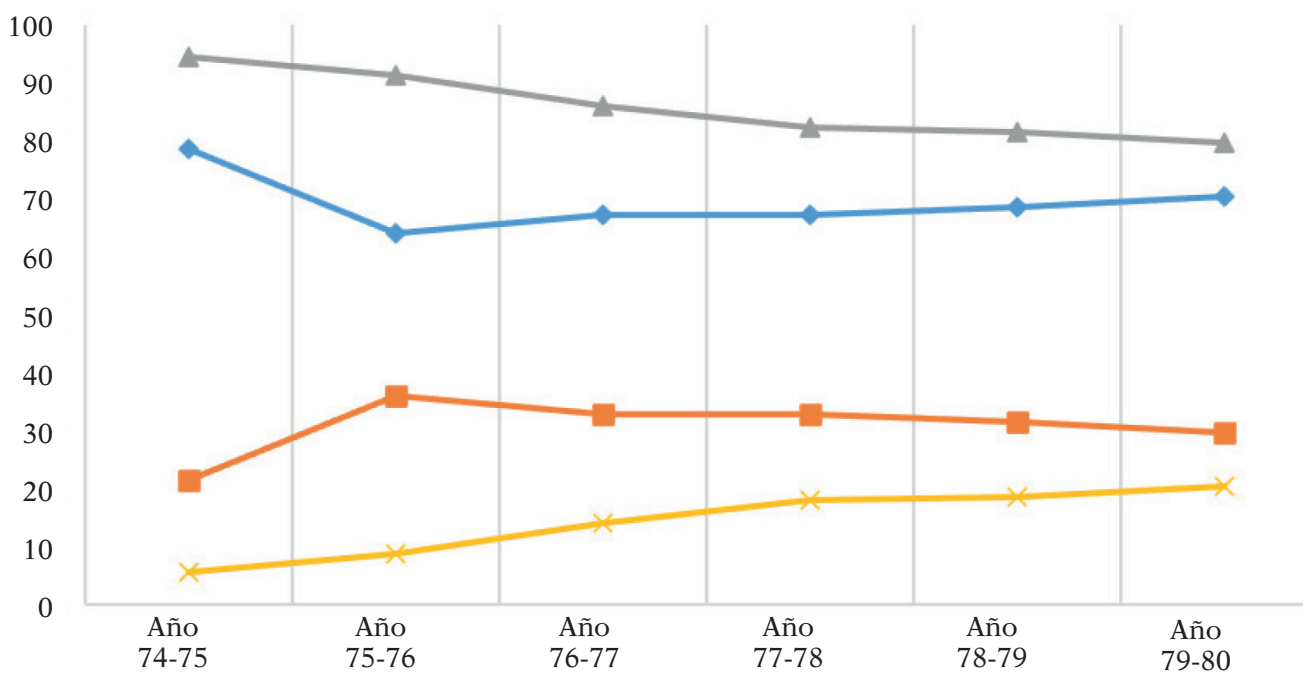

Al igual que el alumnado, también el profesorado de magisterio tiene un porcentaje femenino muy alto, mucho más que en cualquier otra escuela o facultad universitaria. En las escuelas estatales, en el curso 1980-1981, supone el 47,6\%,50 mientras que en las escuelas de la Iglesia es de un $47,2 \%,{ }^{51}$ prácticamente igual. En Escuni, sin embargo, el número de profesoras asciende al $71 \%$ del total. ${ }^{52}$ Estas cifras muestran la continuidad histórica en la relación entre el mundo femenino y la educación en sus niveles inferiores.

A partir de la aprobación de la constitución en 1978 el principio de igualdad queda sancionado en el artículo 14, y sirve de base a las aspiraciones femeninas, ancestralmente relegadas. Las mujeres cada vez son más conscientes de la posibilidad de elegir su destino y de la necesidad de aspirar a una buena formación. La Ley General de Educación de 1970

\footnotetext{
50 Varela y Ortega, El aprendiz de maestro, 167.

51 «IV Asamblea de Escuelas Universitarias de Magisterio de la Iglesia», 25 de marzo de 1983, carpeta Asambleas, caja 4, AHE

52 «Libro de altas y bajas del profesorado». Administración, AHE.
} 
ya había unificado el diseño curricular entre hombres y mujeres, a pesar de que sabemos que los sesgos se mantenían en el currículum oculto. ${ }^{53}$ Pero la sociedad española cambia rápidamente y permite el ascenso y promoción de las mujeres en diferentes campos. El trabajo de las hijas en el hogar no es tan preciso como lo fue en otras épocas, y sin embargo en las familias jóvenes cada vez es más necesaria la aportación del sueldo de los dos miembros. En este caso la escuela es reflejo de la sociedad ${ }^{54} \mathrm{y}$ las mujeres mejoran su formación y su ocupación frente a sus progenitoras. La profesión del magisterio sigue manteniendo su primacía en la elección femenina. En las escuelas estatales de formación de maestros y también, y especialmente, en algunas escuelas de la Iglesia, como es el caso de Escuni, se muestra claramente esta tendencia.

\section{CONCLUSIONES}

Los estudios de magisterio constituyeron desde el siglo XIX una de las alternativas de formación, de acceso al mundo cultural y posteriormente laboral más utilizadas por las mujeres. Primeramente, al hacerse completas tanto las escuelas de niños como las de niñas hasta los doce años, se facilitó el progresivo acceso a los institutos de segunda enseñanza. Después, superado el bachillerato elemental el camino hacia el magisterio fue una opción especialmente seguida por ellas. Paralelamente se iban incorporando a los institutos de segunda enseñanza en número cada vez mayor.

Tras la Guerra Civil, a raíz de la Ley de Educación Primaria de 1945, la Iglesia contará con autorización para la apertura de escuelas de magisterio propias, con lo que pronto aumentará la oferta de establecimientos de este tipo, y a la vez, las posibilidades de formación para las mujeres. Al considerarse tradicionalmente el magisterio como una profesión adecuada al papel social que podían desarrollar, estas escuelas se llenaron de alumnado femenino, lo que contribuyó a la feminización del oficio, fenómeno por cierto generalizado en el conjunto de países europeos.

\footnotetext{
${ }_{53}$ Consuelo Flecha García, «Desequilibrios de género en educación en la España Contemporánea: causas, indicadores y consecuencias», Áreas. Revista Internacional de Ciencias Sociales 33 (2014): 49-60. https://revistas.um.es/areas/article/view/216041

54 José Saturnino Martínez García, «Clase social, género y desigualdad de oportunidades educativas en España: 1977-2004», Revista de Educación 342 (2007): 287-306.
} 
El progreso económico de la década de los sesenta tendrá prontas consecuencias sociales y afectará a la necesidad de formación de toda la población. La Ley General de Educación de 1970 será la encargada de actualizar el sistema educativo y de establecer la igualdad en ese campo entre hombres y mujeres. También las antiguas escuelas de magisterio, tanto públicas como de la Iglesia, se verán afectadas por el cambio legislativo y en este momento pasarán formalmente a incorporarse a la universidad. Durante la década de los setenta se disparará la población estudiantil del magisterio, con especial aportación del sector femenino, como hemos visto. En una proporción incluso superior a la de los centros estatales aumentará la población de mujeres en las escuelas de la Iglesia. Entre estas escuelas, algunas serían prácticamente femeninas, pues eran el resultado de la reconversión de varias de las antiguas escuelas de magisterio de la Iglesia procedentes de congregaciones y grupos de Iglesia femeninos.

La clase media baja es el grupo social del que procede el grueso de población que accede al magisterio. El acceso a la cultura, la posibilidad de independencia económica y la elevación social están detrás de la mayor afluencia de mujeres a estos estudios, con pequeñas diferencias en los porcentajes entre escuelas públicas o de la Iglesia.

El caso de Escuni es el ejemplo de escuela de magisterio de la Iglesia que hemos analizado. Surgida en 1970 de la fusión de las escuelas femeninas de Madrid va a tener un rápido aumento de alumnado, incluso mayor al de la media del conjunto de escuelas de la Iglesia en España. Tendrá además una progresión en la afluencia de mujeres que se asentará y ampliará, también en proporciones superiores a las del conjunto de escuelas de la Iglesia. Representa muy bien, pues, el aspecto de feminización de la profesión, siguiendo la tendencia iniciada a principios del siglo XX.

\section{Nota sobre el autor}

Félix Asenjo Gómez es licenciado en Filosofía y Letras, en la Sección de Ciencias de la Educación, por la Universidad Pontificia de Comillas (1986). Diplomado Especialista en Formación de Adultos por la Universidad Autónoma de Madrid (1989). Diploma de Estudios Avanzados de 
la UNED (2010). Actualmente realiza su tesis doctoral en el marco del Programa de Doctorado en Diversidad, Subjetividad y Socialización. Estudios en Antropología Social, Historia de la Psicología y de la Educación de la Universidad Nacional de Educación a Distancia. Imparte como profesor titular las asignaturas de Teoría de la Educación, e Historia y Corrientes Internacionales de la Educación en el Centro Universitario de Magisterio Escuni de Madrid. Desde 2007 hasta 2015 desempeñó en este centro el cargo de Responsable de Área del Departamento de Pedagogía. Última publicación: Educación y europeísmo, un itinerario de encuentro transnacional. Revista Española de Educación Comparada, 36 (julio-diciembre 2020), pp. 14-3. doi: 10.5944/reec.36.2020.261451.

\title{
WEBGRAFÍA
}

\author{
www.escuni.es \\ www.cesdonbosco.com \\ www.lasallecentrouniversitario.es
}

\section{REFERENCIAS}

Alcalde, Fortunato. Cincuenta años de historia (1948-1998). Forjando educadores. Escuela Universitaria La Salle. Madrid: Imprenta Villena, 2001.

Ballarín Domingo, Pilar. «La educación contemporánea de las mujeres». En Historia de la educación en la España contemporánea, diez años de investigación, editado por J. L. Guereña, Julio Ruiz Berrio y Alejandro Tiana Ferrer, 173-190. Madrid: Ministerio de Educación y Ciencia, 1984.

Ballarín Domingo, Pilar. La educación de las mujeres en la España contemporánea (s. XIX-XX). Madrid: Síntesis, 2001.

Carreño, Miryam. «Chicas en la postguerra, un análisis sobre el aprendizaje de género». Historia de la Educación: Revista Interuniversitaria 22-23 (20032004): 79-104.

Escolano Benito, Agustín. «La arquitectura como programa. Espacio-escuela y curriculum». Historia de la Educación vol. XII-XIII (1993-94): 97-120.

Faure, Pierre. «Estudios generales. La enseñanza personalizada, orígenes y evolución». Revista de Educación, 247 (1976): 5-10.

Flecha García, Consuelo. "Profesoras y alumnas en los institutos de segunda enseñanza (1910-1940)». Revista de Educación, núm. extraordinario sobre «La educación en España en el siglo XX» (2000): 269-294. 
Flecha García, Consuelo. «Desequilibrios de género en la educación en la España Contemporánea: causas, indicadores y consecuencias». Áreas. Revista Internacional de Ciencias Sociales 33 (2014): 49-60. https://revistas.um.es/ areas/article/view/216041

Gutiérrez Ruiz, Irene. Experiencia Somosaguas. Madrid: Iter Ediciones, 1971.

Gutiérrez Ruiz, Irene. El maestro de la Experiencia Somosaguas. Tendencias pedagógicas 14 (2009): 181-189.

Guzmán, Manuel de. Vida y muerte de las escuelas normales. Barcelona: PPV, 1986.

Holgado Barroso Juan, José Márquez de la Plata y Manuel Martín Riego. De la Escuela de Magisterio de la Iglesia al CES Cardenal Spínola CEU (1957-2011): historia de una institución. Sevilla: Fundación Universitaria San Pablo CEU, 2013.

Landsheere, Gilbert de. La formación de los enseñantes de mañana. Madrid: Narcea, 1979.

Lerena Alesón, Carlos. «El oficio de maestro. La posición y papel del profesorado de primera enseñanza». Sistema. Revista de Ciencias Sociales 50-51 (1982).

Martínez García, José Saturnino. «Clase social, género y desigualdad de oportunidades educativas en España (1977-2004)». Revista de Educación 342 (2007): 287-306.

Matas Pastor, Joan Josep. Las Hermanas de la Pureza de María en la formación de maestros y comunicadores. Historia del Centro de Enseñanza Superior Alberta Giménez (1974-2014). Madrid: Universidad Pontificia Comillas, 2015.

Mencía, Emiliano. «Escuelas unidas-escuela universitaria». En Veinticinco años abriendo horizontes. Escuni 1970-1995, dir. Dolores María et al. Madrid: Imprenta Artegraf, S.A. 1995.

Muñoz Vitoria, Fernando. El sistema de acceso a la universidad en España (19401990). Madrid: Ministerio de Educación y Ciencia, C.I.D.E, 1993.

Ortega, Félix y Agustín Velasco. La profesión de maestro. Madrid: Ministerio de Educación y Ciencia, CIDE, 1984.

Ortega Gutiérrez, Félix. «Un pasado sin gloria. La profesión de maestro». Revista de Educación 284 (1987).

Puelles Benítez, Manuel de. «Oscilaciones de la política educativa en los últimos cincuenta años: reflexiones sobre la orientación política de la educación». Revista Española de Pedagogía 192 (1992): 311-319.

Rabazas Romero, Teresa y Sara Ramos Zamora. «La construcción del género en el franquismo y los discursos educativos de la Sección Femenina». Encounters on education=Encuentros sobre educación=Recontres sur l'éducation, 7 (2006): 43-70.

Tena Artigas, Joaquín, Luis Cordero Pascual y José Luis Díaz Jares. La educación en España, análisis de unos datos. Madrid: Ministerio de Educación y Ciencia, 1978. 
Toledo, Genoveva. «Las escuelas de magisterio de la Iglesia en Madrid y su aportación a la formación de maestros (1945-1970)». PhD diss., Universidad Complutense de Madrid, 1984.

Varela, Julia y Félix Ortega. El aprendiz de maestro. Madrid: Ministerio de Educación y Ciencia, 1984.

Viñao Frago, Antonio. Escuela para todos. Educación y modernidad en la España del siglo XX. Madrid: Marcial Pons, 2004.

Zaballos Crespo, Josefa. Origen y evolución histórica de la escuela universitaria «Don Bosco». Madrid: Servicio de Publicaciones de la Universidad Complutense, 2005. 